\title{
Active Disturbance Rejection Control of Shell Gasifier in IGCC Power Plants
}

\author{
Chen Shihe ${ }^{1 *}$, Luo Jia ${ }^{1}$, Wu Le ${ }^{1}$, Zhang Yuqiong $^{2}$, Li Donghai $^{2}$ and Xue Yali ${ }^{2 *}$ \\ ${ }^{1}$ Electric Power Research Institute of Guangdong Power Group Co., \\ Guangzhou, 510080 China \\ ${ }^{2}$ Key State Lab of Power Systems, Thermal Engineering Department, Tsinghua \\ University, Beijing, 100084 China \\ chen_shi_he@163.com,xueyali@tsinghua.edu.cn
}

\begin{abstract}
A unique control strategy based on Active Disturbance Rejection Control (ADRC) is introduced to the Shell gasifier control system. Firstly, the gasifier control system structure is illustrated based on the analysis of gasifier process dynamics and its control targets. Then a decentralized ADRC-based gasifier control system is designed and the controller parameter tuning procedure is given. The interaction of control loops, the uncertainties in the plant and the ignored dynamics in modeling process are all regarded as the general disturbance, which can be estimated by Extended State Observer (ESO) and then actively compensated in real time. The performance of the proposed control strategy is tested on a Shell gasifier model by simulation experiments, and the Monte-Carlo method is also adopted to test the robustness of the control system. In comparison with the optimized PI controllers with probabilistic robustness, the simulation results show that the designed control system has advantages of better reference-tracking and disturbance-rejection capability, strong robustness and easy tuning procedure.
\end{abstract}

Keywords: Shell gasifier; Active Disturbance Rejection Control; Probabilistic Robustness

\section{Introduction}

The urgent demand of energy and pressure on environment protest exist simultaneously with the rapid economic development in China where more than $60 \%$ of power generation comes from coal, and it is a must to develop the clean coal technology. IGCC (Integrated Gasification Combined Cycle) power plant is one of the promising clean coal technologies, in which the gasifier plays a significant role in producing syngas for the gas and steam combined cycle system. The stable operation of gasifier is the essential precondition of the electricity generation of IGCC power plant. However, the control of gasifier system is difficult due to its multi-variables coupling and various disturbances [1]. Therefore, it is necessary and meaningful to design an appropriate control system for the gasifier system in IGCC power plant.

For the Shell gasifier which is one of the widely used gasifier in the world, Liu et al. [2] built a control-oriented model. Based on the dynamic characteristic analysis of this model, Wei et al. [3] proposed a control strategy using classical PI controllers. Sun et al. [4] designed a Shell gasifier control system using optimized PI controller based on the probabilistic 
robustness under the structure proposed by Wei et al. [3], and compared the control robust performance with Internal Model Control (IMC)-based PI controller. But the application of advanced control strategy is seldom reported in literature and still need further investigation.

Active Disturbance Rejection Control (ADRC) is a unique control technology proposed by Han [5]. The plant is regarded as an integral-cascade connected process, while the model internal uncertainty and the external disturbance are both regarded as a general disturbance, which will be estimated by Extended State Observer (ESO) and compensated by a suitable control law in ADRC framework [5]. Some theoretic analysis, such as frequency domain method [6-8], time domain method [9-11], have been studied to explore the ability of ADRC, especially on the stability of the ADRC for various plants, including linear time-invariant plant with highly uncertainty, nonlinear time-variant system with unknown dynamics, nonlinear systems with uncertainty, etc. The application of ADRC on practical plants has also been reported in many fields, such as missile servo system with large loads [12], MEMS Gyroscope control system [13-17], web tension and velocity regulation [18-19], chemical processes [20], hydraulic turbines [21], thermal power plants [22], etc. ADRC has also been applied to Alstom gasifier benchmark problem by Huang [23]. All these application suggest the huge potential of ADRC in the real industrial control.

In this paper, a gasifier control system based on ADRC was designed, in which the uncertain dynamics and external disturbance were regarded as an extended state of the system and were estimated and compensated by ADRC in real time. The structure of this paper is as follows: In Section 2, the gasifier control problem was illustrated and the Shell gasifier model was introduced; Section 3 described the design of ADRC-based Shell gasifier control system, including the control structure, the basic principle of the adopted first-order ADRC and the controller parameter tuning procedure. Some simulation experiments were given in Section 4, and compared with the optimized PI control system proposed in [4], and also Monte-Carlo method was adopted to test the robustness of the gasifier control system. Finally, some conclusions were given in Section 5.

\section{Problem Formulation}

A schematic diagram of the Willem Alexander IGCC power plant in Buggenum [24], which is the first commercial IGCC plants in the world, is shown in Figure 1, and a Shell gasifier is employed in this power plant.

As one of the important parts in IGCC power plant, the gasifier is to produce suitable syngas as the fuel of gas and steam combined cycle system. Usually, two variables should to be controlled in gasifier system, including gasifier temperature and the heat value of the syngas. The gasifier temperature is one of the key factors determining the compositions of the syngas, and it must to be maintained at a desired value, this is because that many complex chemical reactions occur in the gasifier, and specific reaction demands particular temperature. The heat value of syngas is another important controlled variable, since it is one of the major measurable indicators of syngas quality. The heat value of syngas responses to the change of the gasifier load condition or the feed coal quality, and the fluctuation of the heat value will affect the power generation of the conventional combined cycle system in IGCC power plant. Moreover, the combustion chamber of the gas turbine is usually designed for a specific range of heat value of syngas, so the heat value change of syngas may affect the combustion efficiency of the gas turbine and reduce the efficiency of the whole IGCC power plant. 


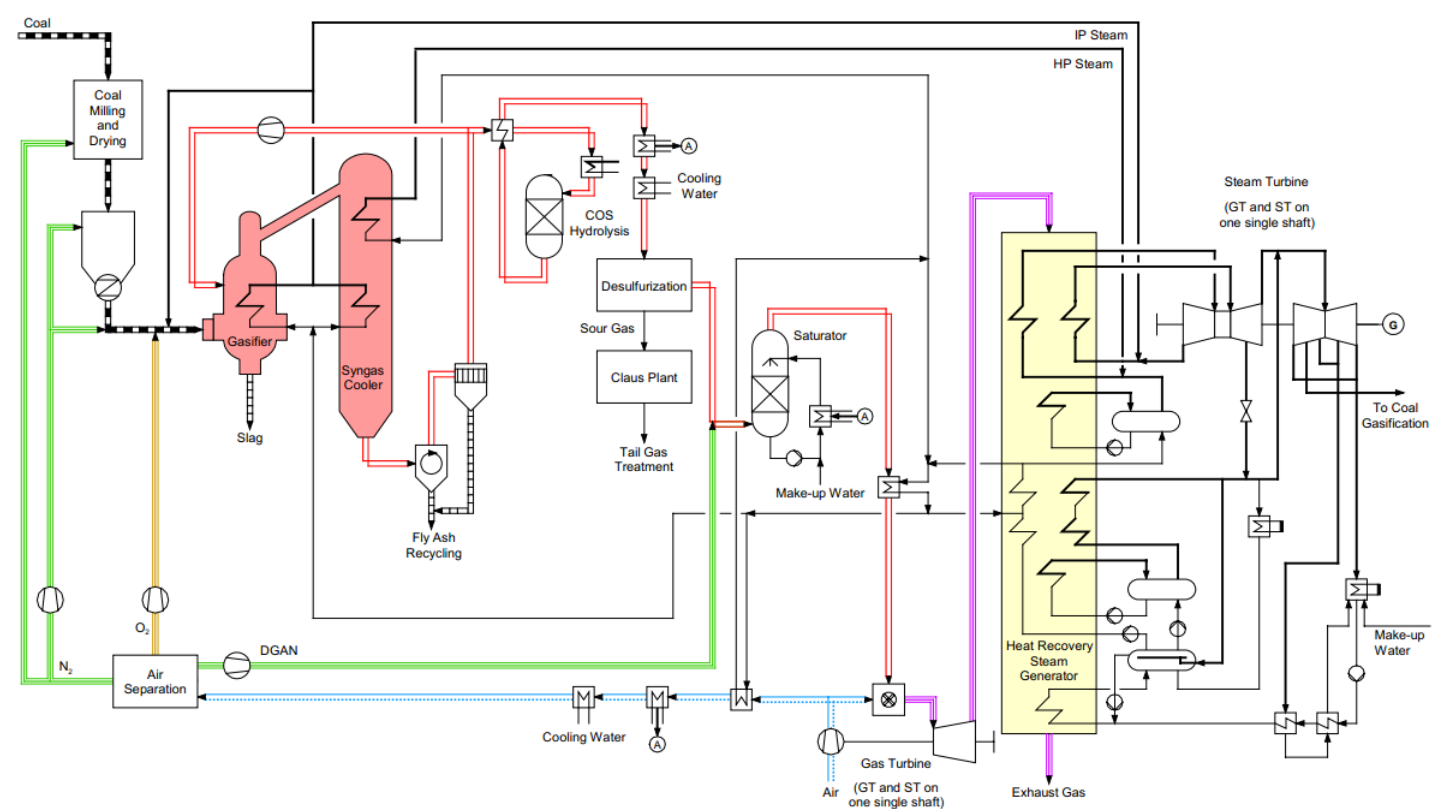

Figure 1. Schematic Diagram of IGCC Power Plant

Based on the analysis of the Shell gasifier and IGCC power plant, a control system structure [3] was designed as shown in Figure 2. The gasifier controller is part of IGCC power plant control system. Basically, the IGCC plant load is regulated by syngas flow rate, which is one of gasifier system outputs and determined by the feed flow rate of oxygen, coal and steam simultaneously. The flow rate of oxygen is selected as the output of load controller based on the dynamic characteristic analysis of Shell gasifier, while two proportional controllers are introduced to decouple the load controller and gasifier controller. Based on that, the gasifier temperature and syngas heat value are regulated by feed steam flow rate and coal flow rate, respectively.

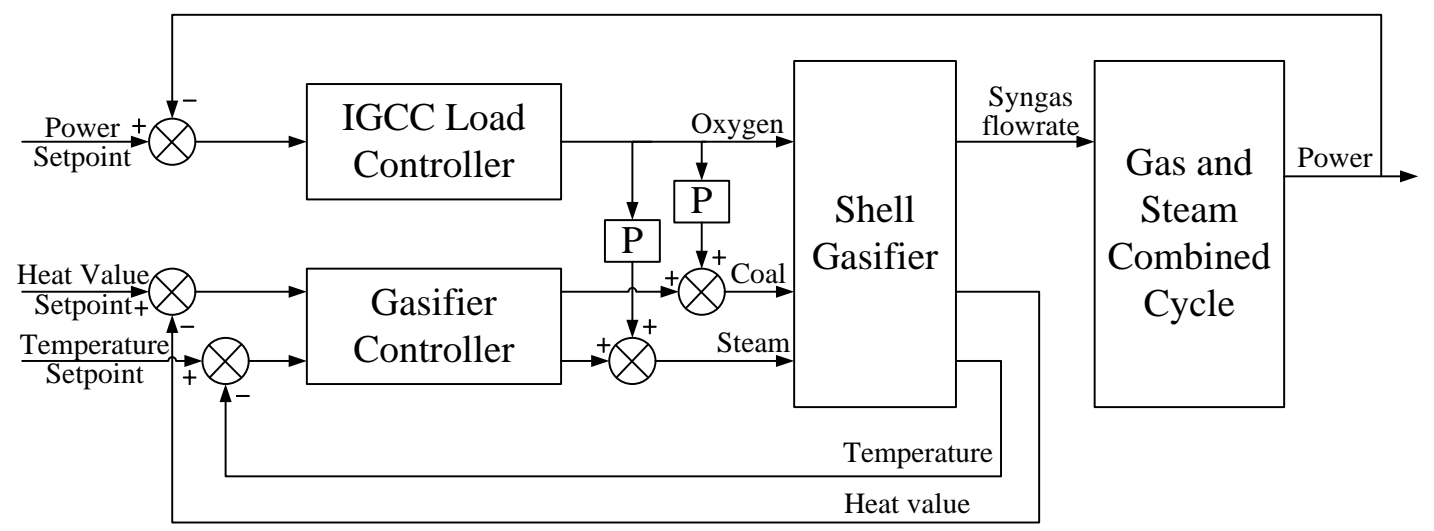

Figure 2. Schematic Diagram of IGCC Power Plant Control System

Liu et al. [2] built a Shell gasifier model and then simplified it as a transfer function matrix to facilitate the control system design, as shown in (1). 


$$
\left[\begin{array}{l}
d \mathrm{~T} \\
d \mathrm{HV}
\end{array}\right]=\left[\begin{array}{ccc}
\frac{25(164 s+1)}{(128 s+1)(50 s+1)} & \frac{-19.8(184 s+1)}{(108 s+1)(60 s+1)} & \frac{-2.8(300 s+1)}{(158 s+1)(15 s+1)} \\
\frac{-1.8}{10 s+1} & \frac{1.75}{10 s+1} & 0
\end{array}\right]\left[\begin{array}{l}
d \mathrm{O}_{2} \\
d \text { Coal } \\
d \text { Steam }
\end{array}\right]
$$

Where, $d \mathrm{O}_{2}, d$ Coal and $d$ Steam are the flowrate variation of oxygen, coal and steam, $d \mathrm{~T}$ and $d \mathrm{HV}$ are the variation of gasifier temperature and syngas heat value, respectively.

\section{Active Disturbance Rejection Control of Shell Gasifier}

\subsection{Principle of ADRC}

Consider a general process which can be expressed as follows

$$
\dot{y}=g(y, \ddot{y}, \ldots, t)+w+b u,
$$

Where $y$ and $u$ are the output and input of the process, respectively, $b$ is a coefficient. $g(y, \ddot{y}, \ldots, t)$ represents the internal disturbance and uncertainties, and $w$ is the external disturbance. $g(y, \ddot{y}, \ldots, t)$ and $w$ are considered as a kind of general disturbance in ADRC, denoted as $f(y, \ddot{y}, \ldots, t, w)$. So the process can be expressed as a one order process:

$$
\dot{y}=f(y, \ddot{y}, \ldots, t, w)+b u \text {. }
$$

Then, a second-order extended state observer (ESO) is constructed as below.

$$
\left\{\begin{array}{l}
\dot{z}_{1}=z_{2}+\beta_{1}\left(y-z_{1}\right)+b_{0} u \\
\dot{z}_{2}=\beta_{2}\left(y-z_{1}\right)
\end{array},\right.
$$

Where $\beta_{1}, \beta_{2}$ and $b_{0}$ are the tunable parameters of ESO, $z_{1}$ and $z_{2}$ are the outputs of ESO, which are expected to track closely the dynamic of $y$ and $f$ of (3), respectively. The parameters $\beta_{1}$ and $\beta_{2}$ determine the velocity and accuracy of the ESO and $b_{0}$ should be well-estimated so that it is approximated to $b$ in the process.

If the control law is designed as:

$$
u=\left(u_{0}-z_{2}\right) / b_{0},
$$

and general disturbance $f$ can be observed by $z_{2}$, then we have

$$
\dot{y}=f(y, \ddot{y}, \ldots, t, w)+b_{0} u \approx z_{2}+b_{0}\left(u_{0}-z_{2}\right) / b_{0} \approx u_{0}
$$


It is a one-order integral process and can be easily controller by a state feedback controller with proportional form:

$$
u_{0}=k_{p}\left(r-z_{1}\right) \approx k_{p}(r-y)
$$

where $r$ represents the set point. Substitute (7) into (6), the closed-loop dynamic equation is as below.

$$
\dot{y}+k_{p} y=k_{p} r
$$

Hence, the closed-loop transfer function is obtained as a first-order system, where parameter of the proportional controller $k_{\mathrm{p}}$ should be tuned according to the performance specifications.

$$
G_{c l}=\frac{Y(s)}{R(s)}=\frac{k_{p}}{s+k_{p}} .
$$

Based on the description of the first-order ADRC above, its control block diagram is shown in Figure 3.

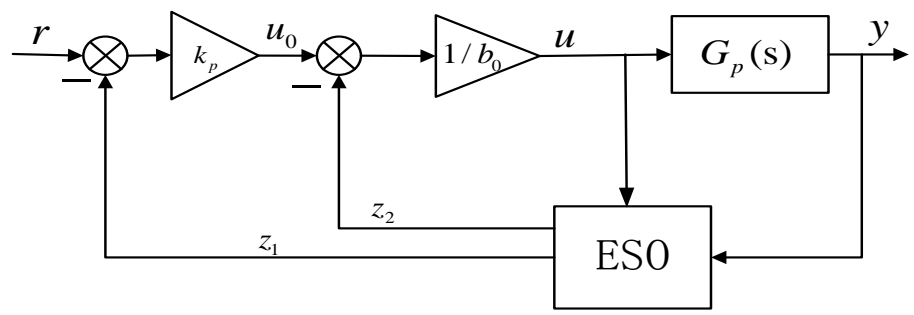

Figure 3. Block Diagram of First-Order ADRC

\subsection{Control System Structure}

The gasifier controller consists of two ADRC controllers, and the control diagram is shown in Figure 4, in which $y_{1}$ and $y_{2}$ represent gasifier temperature and syngas heat value, $r_{1}$ and $r_{2}$ represent their set points, $u_{1}$ and $u_{2}$ are feed flow rate of steam and coal, respectively. It should be noticed that the Shell gasifier process is a multivariable system of $3 \times 3$, but only $2 \times 2$ process is considered in the gasifier controller design, and the variation of oxygen flow rate in Figure 3 is regarded as the external disturbance into the $2 \times 2$ gasifier control system. Moreover, the decentralized structure is adopted, so the interaction between two loops can also be regarded as the external disturbance of each loop. All these disturbance are estimated by ESO and will be compensated by an appropriate control law in real time. 


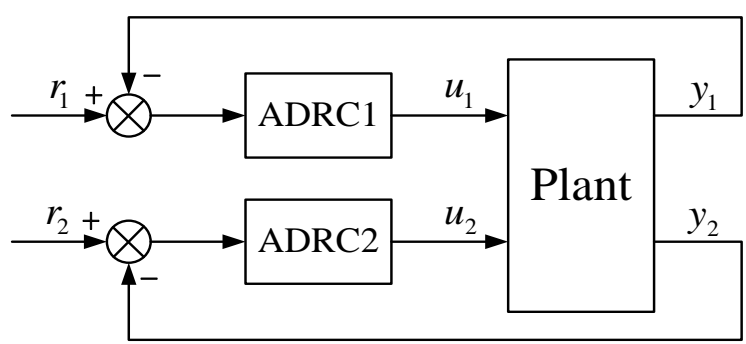

Figure 4. Schematic Diagram of Decentralized ADRC System for $2 \times 2$ System

\subsection{Parameter Tuning}

A transfer function model is identified as shown in (10) and adopted in this paper to design the ADRC control system:

$$
\left[\begin{array}{l}
y_{1} \\
y_{2}
\end{array}\right]=\left[\begin{array}{ll}
G_{11}(s) & G_{12}(s) \\
G_{21}(s) & G_{22}(s)
\end{array}\right]=\left[\begin{array}{cc}
\frac{-2.8(300 s+1)}{(158 s+1)(15 s+1)} & \frac{-19.8(184 s+1)}{(108 s+1)(60 s+1)} \\
0 & \frac{1.75}{10 s+1}
\end{array}\right]\left[\begin{array}{l}
u_{1} \\
u_{2}
\end{array}\right]
$$

Step 1: Tuning of Parameter $\boldsymbol{b}_{\mathbf{0}}$. The parameter $b_{0}$ of ADRC1 and ADRC2 is estimated based on the diagonal transfer function. Taking $G_{11}(s)$ as an example, the relation between $y_{1}$ and $u_{1}$ can be written as:

$$
2370 \ddot{y}+173 \dot{y}+y=-840 \dot{u}-2.8 u,
$$

which can be transformed into the equation as below.

$$
\begin{aligned}
& \dot{y}=\frac{-2370 \ddot{y}-y-840 \dot{u}-2.8 u}{173}=f-\frac{2.8}{173} u \\
& f=\frac{-2370 \ddot{y}-y-840 \dot{u}}{173}
\end{aligned}
$$

So the value of $b_{0}$ for ADRC1 is calculated as $-2.8 / 173$. The parameter $b_{0}$ for ADRC2 can be obtained in the same way.

Step 2: Tuning of $\beta_{1}, \beta_{2}$ and $\boldsymbol{k}_{\mathbf{p}}$. A practical method based on scaling and bandwidthparameterization [25] is adopted in this paper. Based on analysis using the observer standard eigenvalue assignment technique and the parameterization of the observer and state feedback controller, the parameters $\beta_{1}, \beta_{2}$ and $k_{\mathrm{p}}$ can be converted into the functions of the observer bandwidth $\omega_{o}$ and controller bandwidth $\omega_{c}$, which can be expressed as follows: 


$$
\left\{\begin{array}{l}
\beta_{1}=2 \omega_{o} \\
\beta_{2}=\omega_{o}^{2} \\
k_{p}=\omega_{c}
\end{array}\right.
$$

Then, referring to the tuning method for second-order ADRC, the adjustment of the values $\omega_{o}$ and $\omega_{c}$ can be obtained based on the desired settling time of the system, denoted as $t_{s}$. According to equation (9), the desired unit step response in frequency domain of the plant with a first-order ADRC will be:

$$
Y(s)=\frac{k_{p}}{s+k_{p}} \cdot \frac{1}{s}=\frac{1}{s}-\frac{1}{s+k_{p}}=\frac{1}{s}-\frac{1}{s+\omega_{c}}
$$

Thus, the unit set point step response of the system is:

$$
y(t)=L^{-1}[Y(s)]=1-e^{-\omega_{c} t_{s}}
$$

According to the definition of the settling time for $2 \%$ error range and equation (15), $\omega_{c}$ can be calculated as $\omega_{c}=3.912 / t_{s}$. After that, the bandwidth of ESO $\omega_{o}$ is usually calculated as $\omega_{o}=10 \omega_{c}$ according to Ref [25]. Then the parameters $\beta_{1}, \beta_{2}$ and $k_{\mathrm{p}}$ are determined by (13).

Step 3: Refine Tuning of Parameters. Above tuning are based on diagonal elements of transfer function model. Based on that, the parameters are finely tuned to meet the specifications according to their following impact on dynamics [26]:

1) A larger $\omega_{o}$ brings a faster ESO. The bigger $\omega_{o}$ becomes, the sooner the disturbance is observed and cancelled by the controller, but this results in the sensitivity to noises. So $\omega_{o}$ need to be optimized from the initial value, subject to the condition that the stability should be guaranteed and the fluctuation could be acceptable.

2) Larger $\omega_{c}$ or smaller $b_{0}$ usually lead to stronger control action, i.e. a faster response and more violent fluctuations at the same time.

After the controller parameters were acquired by the three steps described above, the values are shown in Table 1.

Table 1. Parameter Values of ADRC Controllers

\begin{tabular}{llll}
\hline Controller & $b_{0}$ & $\omega_{c}$ & $\omega_{o}$ \\
\hline ADRC1 & -0.8 & 3.192 & 31.92 \\
ADRC2 & 0.175 & 1.2768 & 12.768 \\
\hline
\end{tabular}




\section{Simulation Result and Analysis}

\subsection{Dynamic Performance Test}

The set point tracking performance of gasifier temperature and syngas heat value were firstly tested based on nominal model, then a disturbance of oxygen flow rate was added to the plant. The dynamic performance was compared with the optimized PI controllers based on probabilistic robustness, which was proposed in Ref [4] and has been proved to make a comprehensive consideration for a variety of specific demands put forward by industrial community and present the superiority on both external disturbance rejection and coupling resistance [4].

At time $t=1 \mathrm{~s}$, a gasifier temperature set point step was added to the system, and then at $t$ $=5 \mathrm{~s}$, the syngas heat value set point step was introduced, and at time $t=15 \mathrm{~s}$, an external oxygen disturbance was occurred. The dynamic response is shown in Figure 5-6. The performance indicators are shown in Table 2.

Table 2. Dynamic Performance Comparison

\begin{tabular}{clll}
\hline \multirow{2}{*}{ Control System } & Controlled variable & $\begin{array}{c}\text { Settling time } \\
(2 \%)(\mathrm{s})\end{array}$ & $\begin{array}{c}\text { Overshoo } \\
\text { t }\end{array}$ \\
\hline \multirow{2}{*}{ ADRC control system } & Gasifier temperature & 0.9 & 0.15 \\
\cline { 2 - 3 } & Syngas heat value & 2.13 & 0.00037 \\
Sptimized PI control $^{[4]}$ & Gasifier temperature & 1.26 & 8.36 \\
& Syngas heat value & 3.4 & 12.69 \\
\hline
\end{tabular}
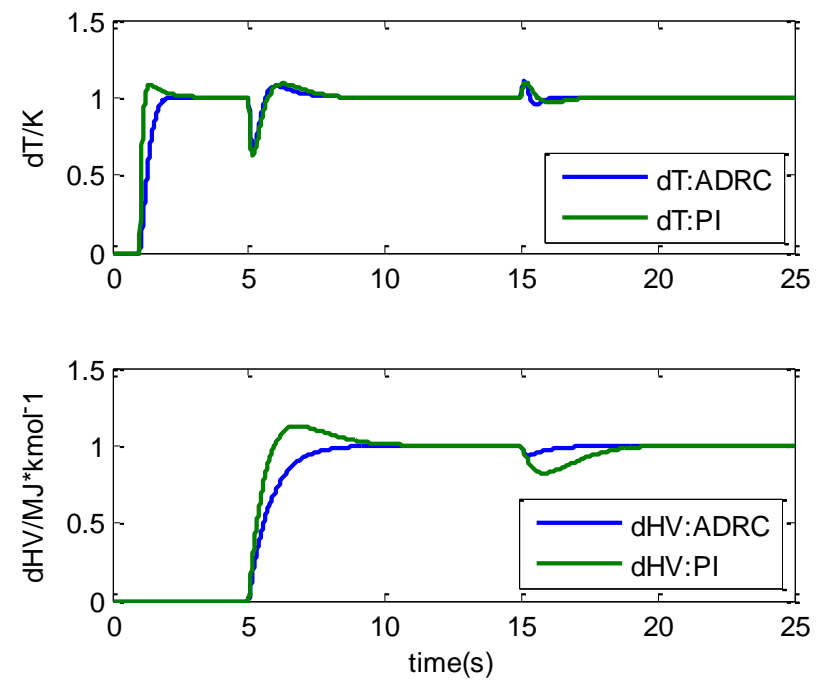

Figure 5. Gasifier Temperature and Syngas Heat Value 

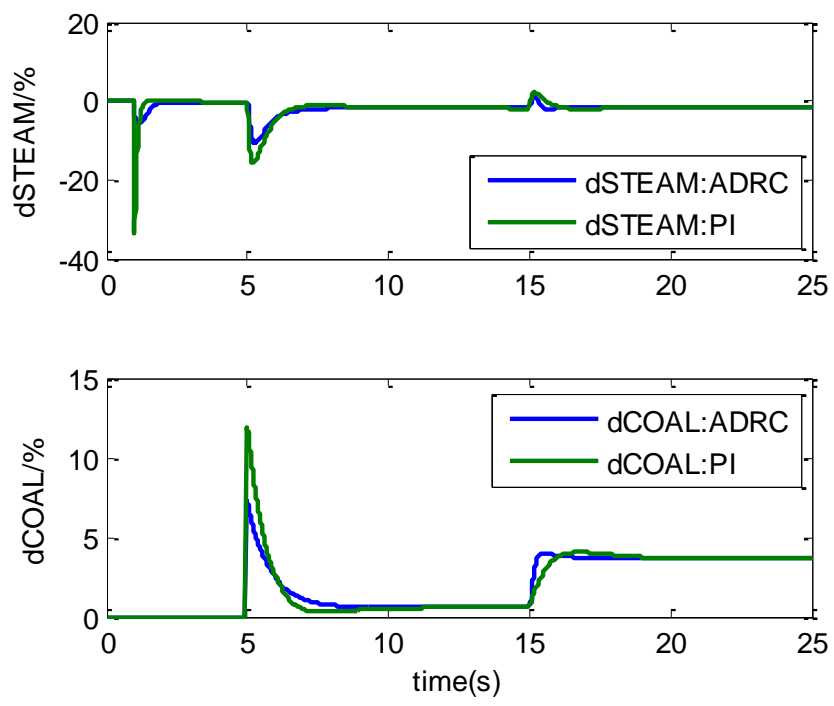

Figure 6. Steam and Coal Flow Rate

It is obvious that the control system based on ADRC presents better set point following capacity in both loops in comparison with the optimized PI control system. Besides, the coupling between two loops is effectively attenuated in ADRC-based control system. Another apparent merit of proposed method is the strong rejection ability against the oxygen flow rate disturbance, which will play a significant role in reducing the coupling between IGCC load control system and gasifier system. In the aspect of control output, the ADRC-based control system has smaller fluctuation amplitude of coal and steam mass rate during transient process, which suggests energy saving and economic benefit in practical industrial process.

\subsection{Robust Performance Test Based on Monte-Carlo Method}

It is unavoidable that there are various uncertainties and time-variant factors in actual gasifiers which are not described in the model. Therefore, it is necessary to test the control performance with the change of the plant, which represents the robustness of the control system. Referring to paper [27], the experiments based on Monte-Carlo method were carried out with the variation of the model. During the experiments, all coefficients of the model as shown in equation (1) are all assumed to have $\pm 20 \%$ independent uniform distributions around their nominal value, while the controller parameters keep the same. The experiments are repeated until the range of responses of the system is nearly unchanged. The results of such a robustness test are shown in Figure 7 and Figure 8, which illustrate each response to a plant with randomly changed parameters around the nominal value. Figure 9 shows the distribution of the settling times and overshoots in a 2-D space, in which the horizontal axis and vertical axis are the overshoot and settling time, respectively. Accordingly, a more densely distribution of these points indicates a stronger robustness of control system, and the closer distribution to the origin of coordinate demonstrates better performance. 

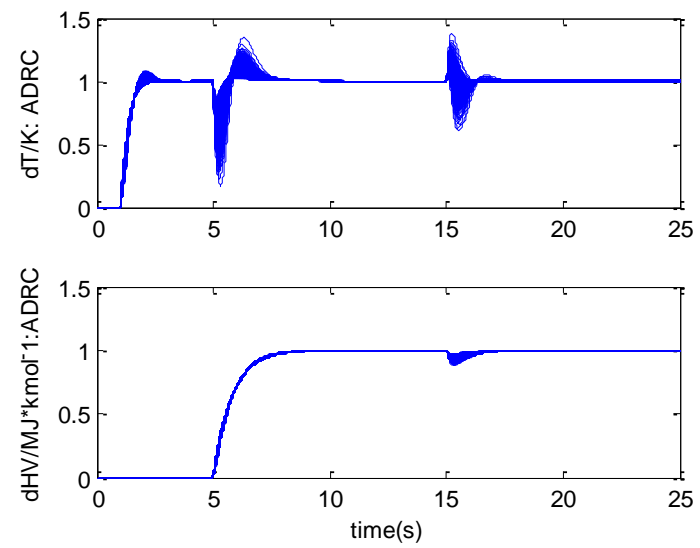

Figure 7. ADRC-Based Gasifier Control with Monte-Carlo Experiments
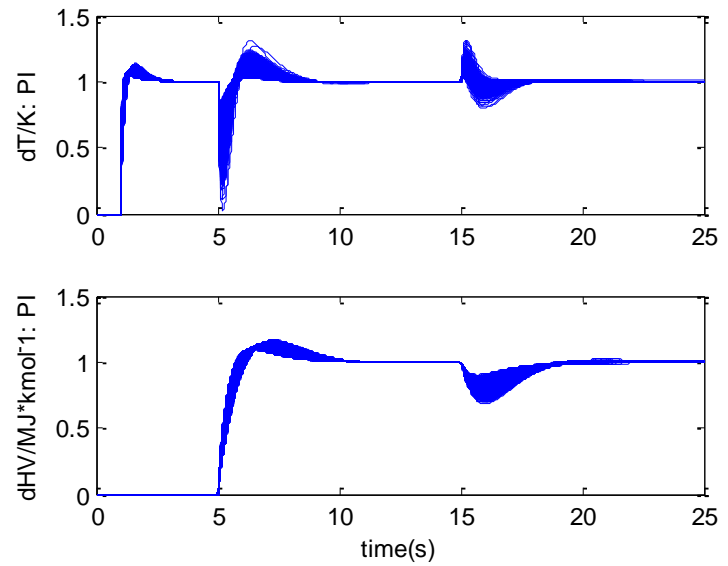

Figure 8. Optimized PI-Based Gasifier Control with Monte-Carlo Experiments

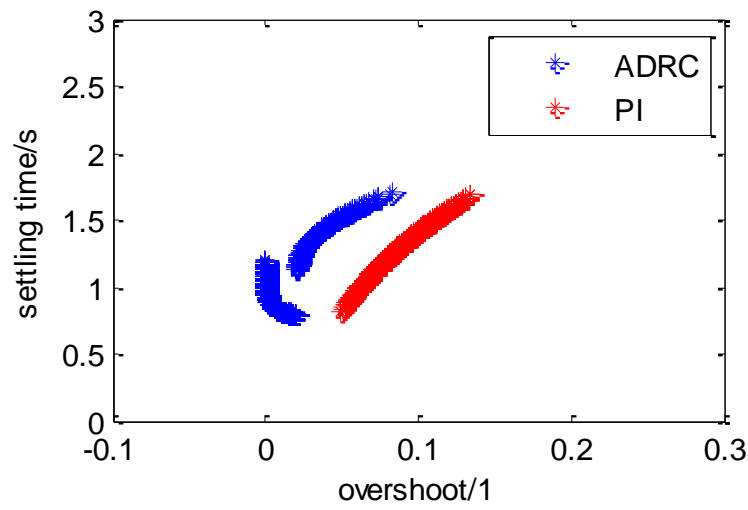

Figure 9. Distribution of Settling Time and Overshoot with Monte-Carlo Experiments 
As is shown in Figure 7 and 8, the variation range of the syngas heat value in ADRC-based control system is evidently smaller than that of the control system with optimized PI based on probabilistic robustness. The response variation range of temperature is also smaller or almost the same as that of the compared PI control system. According to the distribution of performance indicator points in Figure 9, the robustness of the designed ADRC-based gasifier control system can reach the level of the system with PI controllers, which has been optimized based on probabilistic robustness. Therefore, the robustness of the proposed control system is strong enough without any complex optimization process based on some robustness-relatively criterions.

\section{Conclusion}

In this paper, a gasifier control system based on active disturbance rejection control is designed on Shell gasifier model. Two first-order ADRC controllers with decentralized control structure were applied to the plant, and an appropriate tuning procedure was given to obtain a desired performance. In order to test its control performance, some simulation experiments are taken when the set point disturbances of gasifier temperature and heat value of syngas and an external oxygen flow rate disturbance were added to the system. In comparison with the control system with optimized PI based on probabilistic robustness, the proposed control system showed a better performance in following reference, decoupling interaction among loops and rejecting external disturbance. Another experiment based on Monte-Carlo method also suggested the strong robustness of the proposed Shell gasifier control system. The results indicate the huge potential of the ADRC controller on the industrial plants like Shell gasifier and offer a new way for the control of gasifier system in IGCC power plant.

\section{Acknowledgments}

This research was supported by the National Natural Science Foundation of China (No. 51176086).

\section{References}

[1] R. Dixon, “Advanced gasifier control”, Computing \& Control Engineering Journal, vol. 10, no. 3, (1999).

[2] S. M. Liu, P. Y. Wang, S. L. Wei and K. X. Kou, "Dynamic model of the gasifier system in IGCC", Gas Turbine Technology, vol. 14, no. 2, (2001).

[3] S. L. Wei, W. D. Ni and S. M. Liu, "Research on gasifier control system in IGCC", Journal of Engineering for Thermal Energy and Power, vol. 17, no. 6, (2002).

[4] L. Sun, D. H. Li, J. Y. Dong and Makeximu, "Optimization of Controllers for Shell Gasifier Based on Probabilistic Robustness", 13th International Conference on Control, Automation and Systems, Gwangju, Korea, (2013).

[5] J. Han, "Active Disturbance Rejection Controller and its Application", Control and Decision, vol. 13, no. 1, (2002).

[6] G. Tian and Z. Gao, "Frequency response analysis of active disturbance rejection based control system", IEEE Multi-conference on Systems and Control, Singapore, (2007) October 1-3.

[7] W. Xue and Y. Huang, "The active disturbance rejection control for a class of MIMO block lower-triangular system", Proceedings of the 30th Chinese Control Conference, Yantai, China, (2011) July 22-24.

[8] D. Wu and K. Chen, "Frequency domain analysis of non-linear active disturbance rejection control via the describing function method", IEEE Trans. Ind. Electronics, vol. 60, no. 9, (2013).

[9] Q. Zheng, L. Q. Gao and Z. Gao, "On estimation of plant dynamics and disturbance from input-output data in real time", IEEE Multi-conference on Systems and Control, Singapore, (2007) October 1-3.

[10] Q. Zheng, L. Q.Gao and Z. Gao, "On stability analysis of active disturbance rejection control for non-linear time-varying plants with unknown dynamics", Proceedings of the 46th IEEE Conference on Decision and Control, LA, USA, (2007) December 12-14.

[11] W. Zhou, S. Shao and Z. Gao, "A stability study of the active disturbance rejection control problem by a 
singular perturbation approach", Applied Mathematical Sciences, vol. 3, no. 10, (2009).

[12] C. Yang and Z. Ke, "Study on the active disturbance rejection control of servo system", International Conference on Computer and Communication Technologies in Agriculture Engineering, (2010), June 12-13.

[13] Q. Zheng, L. Dong and Z. Gao, "Control and rotation rate estimation of vibrational MEMS gyroscopes", IEEE Multi-conference on Systems and Control, Singapore, (2007) October 1-3.

[14] L. Dong, Q. Zheng and Z. Gao, "On control system design for the conventional mode of operation of vibrational gyroscopes", IEEE Sensors Journal, vol.8, no.11, (2008).

[15] L. Dong, Q. Zheng and D. Avanesov, "The design and implementation of driving mode control for vibrational gyroscopes", American Control Conference, Seattle, Washington, USA, (2008) June 11-13.

[16] Q. Zheng, L. Dong, D. H. Lee and Z. Gao, "Active disturbance rejection control for MEMS gyroscopes", IEEE Transactions on Control Systems Technology, vol. 17, no.6, (2009).

[17] Q. Zheng and Z. Gao, "Disturbance rejection in MEMS gyroscope: problems and solutions", Proceedings of the 30th Chinese Control Conference, Yantai, China, (2011) July 22-24.

[18] Y. Hou, Z. Gao, F. Jiang and B. T. Boulter, "Active disturbance rejection control for web tension regulation", Proceedings of 40th IEEE Conference on Decision and Control, Orlando, Florida, USA, (2001) December 4-7.

[19] W. Zhou and Z. Gao, "An active disturbance rejection approach to tension and velocity regulations in web processing lines”, IEEE Multi-conference on Systems and Control, Singapore, (2007) October 1-3.

[20] Z. Chen, Q. Zheng and Z. Gao, "Active disturbance rejection control of chemical processes", IEEE Multiconference on Systems and Control, Singapore, (2007) October 1-3.

[21] L. Dong and Y. Zhang, "On design of a robust load frequency controller for interconnected power systems", American Control Conference, Baltimore, MD, USA, (2010) June 30-July 2.

[22] Q. Zheng, Z. Gao and W. Tan, "Disturbance rejection in thermal power plants", Proceedings of the 30th Chinese Control Conference, Yantai, China, (2011) July 22-24.

[23] C. E. Huang, D. H. Li and Y. L. Xue, "Active Disturbance Rejection Control for the ALSTOM gasifier benchmark problem", Control Engineer Practice, vol. 21, no. 4, (2013).

[24] F. Hannemann, U. Schiffers, J. Karg and M. Kanaar, "V94.2 Buggenum Experience and Improved Concepts for Syngas Applications", Presentation dated, vol. 28, no. 10, (2002).

[25] Z. Gao, "Scaling and bandwidth-parameterization based controller tuning", American Control Conference, Denver, CO, USA, (2003), June 4-6.

[26] Y. Zhang, D. Li and Y. Xue, "Active disturbance rejection control for Circulating Fluidized Bed Boiler", International Conference on Control, Automation and Systems, Jeju, Korea, (2012) October 17-21.

[27] F. Xu, D. Li, X. Jiang. Z. Li and G. Wu, "Monte-Carlo simulation of PID tuning methods", Journal of Tsinghua University, vol. 42, no. 12, (2002). 